\title{
Estudo da Insatisfação do Consumidor nos Serviços Prestados por Assistências Técnicas Autorizadas de Automóveis
}

\author{
Sedinei José Nardelli Beber \\ Carlos Alberto Vargas Rossi
}

\section{RESUMO}

Esta pesquisa consistiu na realização de um estudo exploratório sobre a Insatisfação dos Consumidores com o Serviço de Assistências Técnicas de Autorizadas de Automóveis, investigando as causas, o nível e as consequiências da insatisfação destes consumidores. Este trabalho foi realizado na cidade de Porto Alegre. Como resultados, apresenta-se o perfil dos consumidores, a relação entre o nível geral de insatisfação, a caracterização da amostra e as reações à insatisfação, o relacionamento entre causas e nível de insatisfação e a formação das dimensões de atributos da insatisfação. Entre as conclusões, encontram-se os atributos mais importantes para a insatisfação dos consumidores, a viabilidade do método utilizado para a pesquisa de insatisfação e sugestões para os executivos do ramo evitarem a insatisfação de seus clientes.

Palavras-chave: satisfação; insatisfação; serviços; automóveis.

\begin{abstract}
This research consisted in carrying out an exploratory study about Consumer Dissatisfaction over customer technical assistance at authorized car dealers. The causes, level and of consequences of dissatisfaction were investigated. This study was carried out in the city of Porto Alegre. As pratical results, it shows the customers' profile; the relationship among the general level of dissatisfaction, the sample characteristics and the reactions to dissatisfaction; the relationship between the causes and the level of dissatisfaction; and the formation of dissatisfaction attributes magnitudes. Among the conclusions are the most important attributes to customer dissatisfaction, the viability of method used for dissatisfaction research and suggestions to managers to avoid their customers dissatisfaction.
\end{abstract}

Key words: satisfaction; dissatisfaction; services; car dealers. 


\section{INTRODUÇÃO}

A satisfação pode ser definida, de acordo com Kotler (1998, p. 53), como "o sentimento de prazer ou de desapontamento resultante da comparação do desempenho esperado pelo produto (ou resultado) em relação às expectativas da pessoa". Satisfação não é deixar o cliente surpreso ou alegre, mas atender ou superar as suas expectativas, de modo que fique a contento com os resultados. $\mathrm{O}$ consumidor deve perceber que a troca foi justa, recebendo da empresa um valor que corresponda aos esforços despendidos. Para a empresa, este comprometimento com a satisfação do consumidor deverá ser recompensado, pois hoje há suporte empírico para comprovar que resultados elevados de satisfação dos clientes podem ser acompanhados por uma rentabilidade superior a médio prazo (Anderson, Fornell, \& Lehmann, 1994; Anderson \& Mittal, 1999).

Junto ao estudo da satisfação, tão conhecido, está o estudo da insatisfação. Tão importante quanto conseguir a satisfação do consumidor é evitar a sua insatisfação. Conhecendo como esta ocorre, suas causas e sua relação com aquela, o profissional de marketing conseguirá executar seu trabalho de forma mais eficiente, pois disporá de melhores informações para a tomada de decisão, visando não apenas do aumento da satisfação, mas também à diminuição da insatisfação, podendo utilizar outras técnicas para evitá-la. Do ponto de vista acadêmico, a insatisfação pode sugerir resposta à pergunta de Babin e Griffin (1998, p. 127): "O que mais pode ser dito a respeito da satisfação do consumidor?" referindose ao grande número de pesquisas já publicadas nesta área do conhecimento.

O presente trabalho objetivou analisar a insatisfação dos consumidores a partir dos atributos do serviço analisado. Um trabalho desta natureza mostra-se relevante para as empresas por propiciar-lhes uma ferramenta para maximizar a satisfação dos consumidores por meio da administração da insatisfação geral, a partir do desempenho de seus diferentes atributos, forma de pesquisa bastante usual na análise da satisfação dos consumidores (Hanson, 1992; Wittink \& Bayer, 1994 como citado em Anderson \& Mittal, 1999).

\section{Delimitação do Tema e Problema de Pesquisa}

No contexto da economia, os serviços de assistência técnica são importantes porque representam o final da cadeia na qual se encontram fabricantes de componentes, montadoras e lojistas, chamadas de concessionárias no caso de 
veículos novos. A insatisfação gerada em qualquer parte desta cadeia se refletirá em todos os seus componentes. Neste sentido, a assistência técnica assume papel relevante, porque cumpre a função de solucionar os problemas ocorridos com o cliente mais valioso: aquele que, na etapa anterior da compra, escolheu os produtos da empresa. $\mathrm{O}$ bom atendimento na assistência técnica pode gerar um marketing boca-a-boca extremamente positivo e, mesmo, reverter a insatisfação com um mau atendimento anterior, ao passo que um mau atendimento pode representar a perda definitiva do cliente que escolheu o produto.

Assunto ainda não pesquisado academicamente no Brasil é a insatisfação dos consumidores com a assistência técnica de automóveis, o que inclui desde a mais simples oficina até a mais moderna das concessionárias. Elas são consideradas importantes para os consumidores não só pelos serviços que prestam, mas também por poderem solucionar os problemas de insatisfação com dois grupos de empresas: os fabricantes dos veículos e os responsáveis pela venda, principalmente as concessionárias. Estas normalmente dispõem de boa estrutura para prestação de serviços, sendo as responsáveis pela execução dos trabalhos referentes às garantias dos fabricantes para os produtos novos.

O objetivo geral deste trabalho é verificar as causas, o nível e as consequiências da insatisfação do consumidor com os serviços de assistência técnica de automóveis na cidade de Porto Alegre (RS), complementado pelos seguintes objetivos específicos:

- Descrever as causas de insatisfação dos consumidores com o serviço de assistência técnica de automóveis.

. Descrever o nível de insatisfação dos consumidores com o serviço de assistência técnica de automóveis.

- Descrever as conseqüências da insatisfação dos consumidores com o serviço de assistência técnica de automóveis.

Analisar as relações existentes entre o perfil dos respondentes com causas, nível e conseqüências da insatisfação.

\section{INSATISFAÇÃO DO CONSUMIDOR}

A insatisfação é problema sério, mesmo em economia com elevados padrões de qualidade, como a norte-americana. De acordo com Zemke e Albrecht (como citado em Santos, 1996), um estudo feito pela TARP (Technical Assistance Research Institute) constatou que um entre quatro clientes de empresas médias americanas mudaria de fornecedor, se surgisse uma alternativa razoável. Burke (como citado 
em Hren, 1996) verificou que um consumidor satisfeito chega a comentar sua experiência entre 5 e 8 pessoas, enquanto os insatisfeitos contam para 10 até 16 pessoas. Apesar da subjetividade destes números e das diferenças dos resultados entre diferentes pesquisas desta natureza, o fato é que as experiências negativas aparecem sempre como sendo mais disseminadas do que as positivas.

Este contexto levou ao surgimento do conceito de marketing defensivo, cujo objetivo é diminuir a rotatividade de clientes e a troca de marcas (Fornell \& Wernerfelt, 1987). A razão motivadora é bastante simples: é mais caro obter um novo cliente do que manter um que a empresa já possui. Para a manutenção do cliente é crucial a sua satisfação, pois o momento em que o cliente está mais propenso a trocar de fornecedor é quando está insatisfeito.

Nesse contexto, os processos de reclamação dos consumidores possuem três características básicas. Primeiro, os consumidores possuem objetivos quando reclamam. Eles não reclamam simplesmente por reclamar. Segundo, não existe um padrão de comportamento único, o que faz o consumidor insatisfeito agir de uma série de maneiras diferentes. Por exemplo, ele pode reclamar ao fabricante ou ao varejista. Terceiro, a maioria realiza mais de uma ação de reclamação, não se limitando a apenas uma (Singh \& Wilkes, 1996). Muitas vezes, estes processos podem ocorrer simultaneamente; outras vezes, separadamente, sendo influenciados por diferentes fatores. Como exemplo, tem-se que as variáveis que levam à troca de marca não são necessariamente as mesmas responsáveis pelo boca-a-boca negativo (Richins como citado em Singh \& Wilkes, 1996).

É interessante notar que, apesar dessas características, muitas vezes os consumidores não reclamam para as empresas, que seria o caminho natural para uma possível solução do problema. Para Hepworth (1997), muitos consumidores deixam de reclamar para as empresas pelas seguintes razões:

1. Seria inútil reclamar, pois ninguém na empresa se importa.

2. Não vale a pena, pelo tempo e recursos gastos em reclamar.

3. Não sabem como ou a quem reclamar.

4. Esperam alguma hostilidade ou reação negativa da empresa.

Torna-se fundamental, assim, que a empresa interessada em diminuir o número de consumidores insatisfeitos crie mecanismos que incentivem esses consumidores a reclamarem diretamente para a empresa e, em seguida, tome alguma providência para torná-los satisfeitos.

Nem todo problema, porém, gera insatisfação. Segundo a Teoria da Atribuição (Folkes, 1984), o consumidor é um ser racional que procura descobrir a causa 
responsável pelo seu problema. Se ele se considerar como responsável pelo problema, então, poderá continuar satisfeito e não fazer nada.

Conforme o grau de insatisfação, a resposta varia, normalmente aumentando a reação na medida em que aumenta a insatisfação. $\mathrm{O}$ aumento das reações do consumidor normalmente segue a seguinte direção, conforme sua percepção do problema sofrido (Wilkie, 1994):

1. Não fazer nada.

2. Evitar a marca/vendedor nas transações futuras.

3. Criticar o produto negativamente para os amigos.

4. Procurar uma solução do problema junto ao vendedor.

5. Procurar uma agência fora da transação, como as empresas de proteção ao consumidor ou, em último caso, procurar a mídia e criar um escândalo.

De acordo com Singh e Wilkes (1996, p. 364), "apenas olhando as reclamações como oportunidades, as empresas podem atingir seus objetivos na prestação de serviços sem problemas". As empresas podem tomar uma série de atitudes proativas, visando satisfazer o consumidor acima de suas expectativas e preparando o caminho para resolver eventuais problemas antes que aconteçam. A empresa pode, por exemplo, mandar uma carta cumprimentando o comprador, comprometendo-se a resolver qualquer problema que por acaso ocorra, solicitar sugestões, veicular anúncios mostrando consumidores satisfeitos, mostrar os endereços das assistências técnicas, ter bons canais para atendimento e resolução das queixas, evitando a dupla insatisfação. Para Fornell e Westbrook (1984), as empresas devem criar mecanismos internos para o fluxo das reclamações dos clientes, para que as más notícias cheguem aonde podem ser tomadas as decisões corretivas, sem serem barradas ou deturpadas no caminho por falhas de comunicação interna. Segundo o mesmo autor, o aumento das queixas resulta no aumento dos bloqueios internos da empresa, o que dificulta a resolução dos problemas, criando um círculo vicioso. O inverso também é verdadeiro, porquanto, se a empresa se mostrar receptiva a críticas, os consumidores tendem a comunicar com mais facilidade para a empresa as suas insatisfações (Richins, 1983).

\section{Método}

A pesquisa realizada neste trabalho foi dividida em duas fases distintas. $\mathrm{Na}$ primeira fase, qualitativa, foram realizadas as entrevistas em profundidade e o 
levantamento dos dados secundários. Na segunda fase, quantitativa, foi aplicado um questionário a um maior número de consumidores.

\section{Fase Qualitativa}

Uma das primeiras etapas da pesquisa foi o levantamento dos dados secundários. Estes são definidos como todas as informações obtidas a partir de outros trabalhos, não tendo sido coletadas propositadamente para a pesquisa em estudo (Churchill, 1995), tais como manuais de programas de treinamento das concessionárias, informações sobre atendimento, evolução do faturamento das concessionárias etc. Esta fase objetivou identificar aspectos relevantes da insatisfação dos consumidores e verificar quais atributos são importantes para estes, obtendo um entendimento inicial sobre as causas e consequiências da insatisfação. A escolha das entrevistas em profundidade foi baseada no interesse pelos detalhes pessoais de cada experiência.

Com relação à escolha dos entrevistados, seguiu-se uma série de recomendações de Rossi e Slongo (1997). Foram realizadas 28 entrevistas válidas, sendo 20 com consumidores insatisfeitos e 8 com pessoas relacionadas com os problemas de insatisfação dos consumidores, como mecânicos, consultores técnicos, vendedores de veículos e um representante da Regional Sul de uma montadora. Este número de entrevistas se deve à grande diversidade de problemas encontrados, assim como ao grande número de posturas adotadas pelos consumidores ante estes problemas. A amostra de consumidores insatisfeitos mostrou-se bastante heterogênea.

Os entrevistados da fase qualitativa foram alcançados a partir da relação de consumidores de uma concessionária de automóveis de Porto Alegre, que forneceu o seu cadastro de clientes dos serviços de oficina. Inicialmente, antes da realização das entrevistas, foi necessário separar os consumidores insatisfeitos (objeto desta pesquisa) do grupo total de consumidores. A seleção foi realizada por meio de uma pergunta filtro, feita logo após a apresentação do entrevistador: O senhor já teve alguma experiência de insatisfação com os serviços de reparo ou manutenção de seu veículo na oficina de alguma concessionária? Caso a resposta do entrevistado caracterizasse um consumidor insatisfeito, prosseguiase com a entrevista.

As entrevistas mencionadas foram realizadas utilizando-se um roteiro previamente estruturado. A primeira versão do roteiro foi construída com base na literatura de comportamento do consumidor, leitura de materiais sobre o setor a 
ser analisado e na experiência prévia do pesquisador. Com este roteiro, foram entrevistadas pessoas com conhecimento da problemática de insatisfação dos consumidores com serviços, como funcionários de concessionárias e experts do ramo, como o representante da regional sul de uma das maiores montadoras de automóveis do país.

Finda esta parte, seguiram-se as entrevistas em profundidade com os consumidores insatisfeitos. Para a marcação das entrevistas houve certa dificuldade, pois os consumidores pareciam não desejar lembrar os fatos ocorridos. Esta situação inverteu-se durante a realização delas, quando os entrevistados demonstraram grande interesse no assunto. As entrevistas com este grupo iniciavam-se apresentando o problema de pesquisa, o que em geral levava o entrevistado a falar bastante. Em algumas das entrevistas, tornou-se nítido o desabafo do entrevistado. Quando os assuntos começavam a se esgotar, o roteiro era consultado, impedindo que qualquer tópico planejado deixasse de ser discutido. Em alguns casos, o tópico do roteiro lembrava ao entrevistado uma série de fatos, o que reiniciava a discussão. Por esses motivos, as entrevistas duraram de meiahora a mais de duas horas, participando, por diversas vezes, familiares e colegas de trabalho da pessoa entrevistada.

\section{Fase Quantitativa}

Com os dados da fase anterior foi elaborado um questionário destinado à coleta mais extensa de dados no campo, no qual foram abordadas as questões referentes à insatisfação dos consumidores, os dados sociodemográficos (sexo, idade, estado civil, renda, escolaridade), assim como as questões levantadas na fase qualitativa da pesquisa.

A população deste trabalho foi composta por todos os clientes insatisfeitos de concessionárias de automóveis na cidade de Porto Alegre (RS). Não foi levado em consideração o fato de o consumidor residir em alguma das cidades da região metropolitana, desde que a insatisfação com o serviço tivesse ocorrido com uma das concessionárias da cidade mencionada.

A amostra de 396 casos foi não probabilística, por conveniência, composta de consumidores identificados pelo método descrito na fase qualitativa (pergunta filtro). Toda a amostra foi composta por consumidores dos serviços de assistências técnicas de quatro concessionárias de automóveis em Porto Alegre, entrevistados pessoalmente. O questionário foi pré-testado com 26 clientes insatisfeitos. Foram feitas algumas alterações. Seu formato final básico pode ser visto na Tabela 1 , 
contendo ainda as perguntas referentes ao perfil dos consumidores. Estas questões foram repetidas duas vezes: para Causas de Insatisfação (seção 1, com uma escala de concordância) e para nível de insatisfação (seção dois, com uma escala de pouco a muito insatisfeito).

As entrevistas foram realizadas dentro das concessionárias com entrevistadores treinados, enquanto os consumidores que se julgavam insatisfeitos, normalmente com outra concessionária, aguardavam pelos seus veículos. Desta forma, foi possível obter respostas sem maiores pressões de tempo.

\section{Tabela 1: Análise Fatorial Exploratória dos Atributos do Nível de Insatisfação}

\begin{tabular}{|c|c|c|c|c|c|}
\hline DIMENSÕES & 1 & 2 & 3 & 4 & 5 \\
\hline \multicolumn{6}{|l|}{ Atendimento } \\
\hline 1. Atendentes mostrarem-se zelosos. & 0,817 & & & & \\
\hline 2. Facilidade em fazer o cadastro. & 0,828 & & & & \\
\hline 5. Precisão nas informações do agendamento. & 0,821 & & & & \\
\hline $\begin{array}{l}\text { 6. Retorno das ligações telefônicas prometidas pelos consultores } \\
\text { técnicos. }\end{array}$ & 0,789 & & & & \\
\hline $\begin{array}{l}\text { 7. Comunicações feitas antes de realizarem modificações não } \\
\text { autorizadas. }\end{array}$ & 0,751 & & & & \\
\hline 8. Aviso de que o veículo ficou pronto. & 0,770 & & & & \\
\hline 9. Tolerância com a quilometragem nas revisões. & 0,798 & & & & \\
\hline \multicolumn{6}{|l|}{ Tempo } \\
\hline 12. Tempo de espera para o conserto do veículo. & $\underline{0,420}$ & & & & $\underline{0,593}$ \\
\hline $\begin{array}{l}\text { 13. Tempo de espera para devolução do veículo quando pronto o } \\
\text { serviço. }\end{array}$ & $\underline{0,539}$ & & & & $\underline{0,563}$ \\
\hline 14. Pontualidade no serviço rápido. & 0,622 & & & & \\
\hline 15. Orientação adequada das filas nos atendimentos. & 0,820 & & & & \\
\hline 16. Agilidade no atendimento telefônico. & 0,752 & & & & \\
\hline 17. Tempo de espera para a concessão de crédito. & 0,813 & & & & \\
\hline 18. Tempo de espera para pagamento. & 0,823 & & & & \\
\hline \multicolumn{6}{|l|}{ Diagnóstico e Realização do Conserto } \\
\hline 20. Disponibilidade e adequação das peças. & & 0,685 & & & \\
\hline 21. Descoberta de novos problemas no automóvel. & & 0,688 & & & \\
\hline 22. Conhecimento técnico dos funcionários. & & 0,608 & & & \\
\hline 23. Explicações do orçamento proposto e serviços prestados. & & 0,540 & & & \\
\hline 24. Troca de peças realizada apenas quando necessário. & & 0,479 & & & \\
\hline 25. Problemas mecânicos apontados e não resolvidos adequadamente. & & 0,705 & & & \\
\hline 26. Forma como o automóvel foi conduzido e guardado. & & 0,746 & & & \\
\hline
\end{tabular}




\section{(conclusão)}

Tabela 1: Análise Fatorial Exploratória dos Atributos do Nível de Insatisfação

\begin{tabular}{|c|c|c|c|c|c|}
\hline DIMENSÕES & 1 & 2 & 3 & 4 & 5 \\
\hline \multicolumn{6}{|l|}{ Avaliação Pós-Serviço } \\
\hline 28. Os serviços não corresponderam às promessas feitas. & & 0,804 & & & \\
\hline 29. Serviço bom, mas esperava algo melhor. & & 0,768 & & & \\
\hline 30. Não devolução das peças trocadas. & & & & 0,567 & \\
\hline $\begin{array}{l}\text { 32. Quantidade de retornos para a concessionária até a resolução do } \\
\text { problema encontrado. }\end{array}$ & & 0,647 & & & \\
\hline 33. Realização de todos os consertos pedidos. & & 0,710 & & & \\
\hline $\begin{array}{l}\text { 34. Realização de consertos com qualidade, não gerando novos } \\
\text { problemas. }\end{array}$ & & 0,721 & & & \\
\hline 35. Falta de garantia da concessionária. & 0,622 & & & & \\
\hline 37. Atitudes tomadas pela concessionária após as reclamações. & 0,534 & & & & \\
\hline 38. Dicas para utilização e manutenção do veículo. & & 0,499 & & & \\
\hline \multicolumn{6}{|l|}{ Preço } \\
\hline 40. Preço das autopeças nos consertos. & & & & 0,465 & \\
\hline 41. Preço das horas técnicas dos mecânicos. & & & & 0,694 & \\
\hline 43. Prazos concedidos para pagamentos. & 0,533 & & & & \\
\hline 44. Nota Fiscal/Faturas mal discriminadas e pouco explicativas. & 0,573 & & & & \\
\hline $\begin{array}{l}\text { 45. Serviços gratuitos de praxe não cobrados (como a lavagem do } \\
\text { veículo). }\end{array}$ & & & & 0,695 & \\
\hline \multicolumn{6}{|l|}{ Ambiente } \\
\hline 47. Localização da concessionária. & & & 0,498 & & \\
\hline 49. Estacionamento. & & & 0,574 & & \\
\hline 51. Área de fumantes e não-fumantes. & & & 0,784 & & \\
\hline 52. Adequação da sala de espera. & & & 0,781 & & \\
\hline 53. Acesso à oficina e aos mecânicos & & & 0,761 & & \\
\hline
\end{tabular}

Fonte: coleta de dados.

\section{Relações entre o Nível Geral de Insatisfação e a Caracterização da Amostra}

O relacionamento entre o nível geral de insatisfação e a caracterização da amostra foi verificado por meio do teste qui-quadrado. Encontrou-se uma série de relações entre os diversos itens da caracterização da amostra e o nível geral de insatisfação. De acordo com os resultados, quanto maior a renda familiar, 
quanto maior o grau de instrução, quanto antes aparecerem os problemas no veículo e quanto maior a idade, maior deverá ser o nível de insatisfação. Não mostraram relação significativa com a insatisfação o tempo de espera para levar o veículo ao conserto, o número de pessoas com quem comentou o problema e o número de concessionárias com que trabalhou.

\section{Influencia da Insatisfação Geral nas Reações dos CONSUMIDORES}

Para testar a influência da insatisfação geral sobre as reações dos consumidores realizou-se um teste de comparação das médias, via teste $t$, entre as diferentes reações dos consumidores e o nível geral de insatisfação (Hair, Anderson, Tatham, \& Black, 1998; Manual do SPSS, 1997). Foi realizado um teste para cada tipo de ação possível como consequiência da insatisfação. Para cada tipo de consequiência, um grupo foi considerado como sendo o que tomou determinada ação, e o outro grupo o que não tomou esta ação.

De acordo com os dados, apenas as conseqüências $\mathbf{6}$ - Escrever uma carta à montadora, 7 - Criticar na carta padrão recebida da montadora e 9 Começar um processo judicial possuem resultados estatisticamente diferentes entre o grupo que tomou a atitude e o que não tomou a atitude. Não há, assim, uma relação direta, na maioria das variáveis, no tipo de atitude tomada pelo consumidor e o nível de insatisfação geral. Em outras palavras, para as demais variáveis não se pode dizer que a insatisfação foi determinante na escolha da atitude a ser tomada. Algumas opções foram utilizadas por partes consideráveis da amostra. Outras, por quase ninguém. As atitudes mais tomadas, como 2 Reclamar para o consultor técnico e 3 - Reclamar para o gerente responsável, não forneceram um resultado significante no teste, em sua relação com a insatisfação geral.

As possíveis explicações para estes dados encontram-se na literatura. Conforme Santos (1996), outros fatores, além do sentimento de insatisfação, explicam o comportamento do consumidor. Entre estes fatores pode-se colocar a facilidade em tomar a atitude. O gerente e o consultor técnico estão disponíveis nas prestadoras de serviço, o que torna a reclamação possível e fácil, independentemente do nível de satisfação. É uma situação incentivada por muitas empresas para poderem ter uma segunda chance e obterem a satisfação deste consumidor insatisfeito (Bolfing, 1989). Iniciar um processo judicial, por outro lado, exige desgaste muito maior por parte do consumidor, sendo uma atitude que provavelmente só é tomada, seguindo uma lógica empírica, nos casos muito mais 
graves. Da mesma forma, comentar com outras pessoas parece ser mais uma atitude com grande influência do caráter pessoal, do que simplesmente algo relacionado ao nível de insatisfação.

\section{ConseqüEncias da InSATISFAÇÃo}

A pesquisa também avaliou as conseqüências da insatisfação, conforme levantado na fase exploratória. A maior concordância para reação à insatisfação é reclamar para o gerente responsável (com média simples de 4,34) e para o consultor técnico $(4,02)$. Nota-se, aqui, que o consumidor apresenta uma pequena preferência por quem decide, seguido por quem fez o trabalho.

A concordância com a reação troca de concessionária $(3,25)$ é maior do que para troca de marca de veículo $(2,30)$. Estes resultados podem ser explicados pelo fato de, na fase exploratória, os consumidores terem dito que consideram função da concessionária verificar os veículos antes da entrega, desfazendo qualquer avaria que porventura tivessem, sendo ou não culpa do fabricante. De fato, a maior parte da amostra, $57 \%$, já trabalhou com duas ou mais concessionárias. As atitudes mais drásticas - como iniciar um processo judicial, escrever uma carta à montadora e criticar na pesquisa desta - possuem uma concordância superior à troca de marca/concessionária, apesar da maior dificuldade de operacionalização destas opções por parte do consumidor.

\section{Formação das DiMENSÕES}

A análise fatorial foi realizada neste trabalho para verificar a construção das dimensões utilizadas nas Seções 1 e 2 do questionário. Estas seções foram construídas devido à falta de bibliografia, tendo sido baseadas em informações da fase qualitativa. Para a análise fatorial foram considerados apenas os atributos válidos pela regressão múltipla, eliminando o efeito da multicolinearidade. Com a análise fatorial, é possível analisar estas dimensões e propor modificações que aumentem a sua validade em futuros trabalhos. Os resultados aqui apresentados são da análise fatorial após a realização da rotação varimax, que maximiza as diferenças dos valores entre as colunas, facilitando a interpretação (Hair et al., 1998).

Na Tabela 1 (Análise Fatorial Exploratória dos Atributos do Nível de Insatisfação), encontra-se a análise fatorial exploratória do nível de insatisfação, 
desconsiderando-se os atributos eliminados nas regressões múltiplas. A análise fatorial é aqui interpretada seguindo a ordem dos fatores criados, da maior para a menor variância explicada. Os atributos estão na mesma ordem em que estavam no questionário.

A primeira dimensão criada eqüivale às dimensões Atendimento e Tempo do questionário juntas, criando nova dimensão, onde estão os atributos de ambas. É a dimensão de maior importância, com 31,087\% da variância explicada, conforme a Tabela 2. Esta dimensão recebe as seguintes variáveis, de outras dimensões, que passam a ser entendidas como parte da dimensão Atendimento/Tempo:

. Da dimensão Avaliação Pós-Serviço, recebe a variável 35 (Falta de Garantia da Concessionária) e a variável 37 (Atitudes Tomadas após as Reclamações);

- De Preços, recebe a variável 43 (Prazos concedidos para pagamento) e a variável 44 (Nota Fiscal/Faturas mal discriminadas e pouco explicativas).

A segunda dimensão corresponde à junção de Diagnóstico e Realização do Conserto e Avaliação Pós-Serviço, no questionário original, e que fica com 17,886\% da variância explicada, conforme pode ser visto na Tabela 2. Este segundo conjunto de atributos foi aqui renomeado para Qualidade do Serviço Técnico.

Tabela 2: Resultados Gerais da Análise Fatorial para Nível de Insatisfação com os Dados Significantes da Regressão Múltipla

\begin{tabular}{c|c|c|c}
\hline Fator & Dimensão Aproximada & Eigenvalue & Variância Explicada \\
\hline 1 & Atendimento/Tempo & 18,981 & 31,087 \\
\hline 2 & Qualidade do Serviço Técnico & 10,921 & 17,886 \\
\hline 3 & Ambiente & 5,285 & 8,656 \\
\hline 4 & Preços & 4,981 & 8,158 \\
\hline 5 & Tempo para Conserto e Devolução & 2,193 & 3,592 \\
\hline
\end{tabular}

Fonte: coleta de dados.

Variância Total Explicada: 69,379\%

A terceira dimensão corresponde ao Ambiente, mantendo-se praticamente inalterada, perdendo apenas um atributo por baixa significância na regressão múltipla. Esta dimensão não recebeu nenhum atributo de outra dimensão e também não exportou nenhum.

A quarta dimensão corresponde aos Preços, também com poucas alterações, recebendo o atributo não devolução das peças trocadas. $O$ consumidor 
interpreta, confirmando a lógica das entrevistas em profundidade, que as concessionárias trocam peças além do devido, aumentando os custos.

Surgiu, com variância de apenas 3,592\%, a quinta dimensão, englobando dois atributos de Tempo, os quais também possuem cargas elevadas na nova dimensão Atendimento/Tempo mencionada acima. São as variáveis 12 (Tempo de espera para o conserto do veículo) e 13 (Tempo de espera para devolução do veículo quando pronto o serviço), que sozinhas compõem o quinto fator criado. Estas duas variáveis possuem correlações altas para ambos os fatores: a variável 12, de 0,420 com o Fator 1 (Qualidade do Atendimento) e de 0, 563 com o Fator 5 (Tempo); e a variável 13, de 0,539 com o Fator 1 e 0, 563 com o Fator 5, uma diferença bastante pequena. Pode-se, assim, dizer que estas duas variáveis de tempo estão quase igualmente correlacionadas com os dois fatores.

Apesar dos fracos resultados encontrados para a dimensão Ambiente nos testes, comparando as duas seções (causas e nível de insatisfação), aqui a dimensão Ambiente aparece como um grupo bem discriminado. Como sua variância explicada também é expressiva, sugere que é um grupo pertinente para ser mantido em futuras mensurações do nível de insatisfação dos consumidores de assistências técnicas em concessionárias.

\section{Conclusões}

Uma primeira constatação é o elevado número de reações à insatisfação manifestadas pelos consumidores deste tipo de produto. A maior parte dos consumidores tomou mais de três atitudes, não se limitando a atitudes por voz, como marketing boca-a-boca negativo, mas alguns também tomaram atitudes mais drásticas, como reclamar no Procon e iniciar processo judicial. A explicação para este comportamento pode ser atribuída, em primeiro lugar, ao valor financeiro do produto automóvel. Este produto possui um valor relativamente alto, se comparado com a renda, para a maioria dos consumidores. Logo, devido ao custo, presume-se que os consumidores se tornem mais exigentes com relação aos cuidados com o seu bem. Também devido ao custo, muitas pessoas consideram o automóvel uma reserva de valor, que deve ser preservada. Outra explicação é o elevado nível de envolvimento dos brasileiros com este tipo de produto, povo que, sabe-se, gosta muito de automóveis. Também se observou a grande importância funcional deste produto para a maioria dos entrevistados, sem o qual ocorrem diversos transtornos na rotina.

Uma segunda constatação é a forma como os consumidores reagem, o que 
inclui a troca de concessionária realizada por $75,4 \%$ da amostra. A reação de troca é bastante comum entre os consumidores insatisfeitos, neste caso. Para a escolha da nova concessionária, porém, os consumidores buscam a opinião de amigos e conhecidos, além de utilizarem a nova concessionária de compra para prestação dos serviços. Como a escolha da nova concessionária é feita em parte pela opinião de terceiros, entre os quais se incluem os consumidores satisfeitos, a satisfação também se mostra importante para a obtenção de boas referências junto a possíveis clientes novos, o que inclui os insatisfeitos com a concorrência.

Uma terceira constatação, a partir dos resultados dos cruzamentos, é que não existem relações entre as variáveis sociodemográficas (sexo, idade, renda, grau de escolaridade e estado civil) e as reações à insatisfação. Não é possível, assim, definir quais serão as reações à insatisfação dos consumidores a partir de seu perfil. Foi possível, porém, encontrar grupos significantes com relação ao nível de insatisfação: maior renda, maior grau de escolaridade e faixa etária entre 36 e 55 anos. Os consumidores com estas características possuem os maiores índices de insatisfação, resultado semelhante ao encontrado por Richins (1983).

Uma quarta constatação, com relação aos preços, considerados altos, é que a maior parte dos consumidores declarou que não se incomodaria em pagar se tivesse certeza de que teria todos os problemas resolvidos. Isto ocorre porque, devido aos custos mais elevados das concessionárias, os consumidores possuem a expectativa de que o serviço será próximo da perfeição. Mas, como isto não ocorre, este consumidor mostrou intenção de procurar oficinas não-autorizadas, assim que não houvesse mais o vínculo com a organização responsável pelo pagamento, como uma seguradora ou a garantia do fabricante. Logo, para as concessionárias manterem o cliente das oficinas, é necessário oferecer um serviço impecável.

Com relação às limitações deste trabalho, destaca-se que foi realizado apenas uma vez, em uma única cidade e com apenas um tipo de prestação de serviço. Recomenda-se a outros pesquisadores a realização de trabalhos semelhantes, de modo a testar a confiabilidade dos dados aqui apresentados. Este trabalho também não fez o acompanhamento das reações dos consumidores para conhecer as futuras escolhas em termos de prestadoras de serviços. Para os autores, o trabalho seria bastante enriquecido, se uma futura pesquisa considerasse o relacionamento prévio do cliente com a concessionária, entendendo suas expectativas e sua decisão de compra. A partir deste ponto, comparando-se com os serviços oferecidos, avaliar a sua insatisfação e sua reação. Este procedimento forneceria uma base concreta para um programa de fidelização com amparo no marketing de relacionamento, cujos objetivos de rentabilidade poderiam ser calculados com precisão adequada. 
Com relação a futuras pesquisas, recomenda-se, em primeiro lugar, a replicação do estudo. Em segundo lugar, como sua abrangência ficou restrita à cidade de Porto Alegre, seria interessante aplicá-lo em outras regiões, o que tornaria possível conhecer um pouco as diferenças de insatisfação em diferentes culturas. Em terceiro lugar, a amostra aqui utilizada ficou restrita ao setor de assistências técnicas autorizadas de automóveis. O mesmo método poderia ser utilizado em outros tipos de assistência técnica, tais como assistências de automóveis não-autorizadas, e outros ramos, como consumidores de serviços de eletrodomésticos, aparelhos celulares etc.

Este trabalho, por fỉm, analisou experiências de insatisfação de consumidores do ponto de vista de seus atributos geradores da insatisfação, uma perspectiva em que não foi encontrado outro trabalho semelhante. Como a base teórica mostra evidências de que satisfação e insatisfação não são constructos especulares (Babin \& Griffin, 1998; Bleuel, 1990; Mittal, Ross, \& Baldasare, 1998; Swan \& Combs como citado em Evrard, 1995; Oliver, 1996, entre outros), torna-se necessário aprofundar as pesquisas para conhecer melhor a relação existente entre estes constructos. Anderson e Mittal (1999) sugerem a construção de uma tipologia de atributos, onde cada atributo teria sua influência, assimétrica e não-linear, estudada individualmente, tendo em vista sua influência sobre a satisfação e a insatisfação. A não-linearidade da insatisfação surge, desta forma, como promissora corrente para novas pesquisas.

\section{Artigo recebido em 20.04.2004. Aprovado em 11.08.2004.}

\section{Referencias Bibliográficas}

Anderson, E.,

Fornell, C., \&

Lehmann, D. (1994, July).

Customer satisfaction, market share and profitability: findings from sweden. Journal of Marketing, 68(3), 53-66.

Anderson, E., \&

Mittal, V. (1999).

The satisfaction-profit chain: how solid are the links? [working paper]. Universidade de Pittsburgh.
Babin, B., \&

Griffin, M. (1998, February).

The nature of satisfaction: an updated examination and analysis. Journal of Business Research, 41, pp. 127-136.

Bleuel, B. (1990, Winter).

Customer dissatisfaction and the zone of uncertainty. The Journal of Services Marketing, 4(1), 355-380. 
Bolfing, C. (1989, April/June).

How do customers express dissatisfaction and what can service marketers do about it? Journal of Services Marketing, 3(2), 5-23.

Churchill, Jr., \&

GilbertA. (1995).

Marketing Research: Methodological Foundations (6th ed.). Orlando/FL: The Dryden Press.

Evrard, Y. (1995).

A satisfação dos consumidores: a situação das pesquisas (tradução não publicada).

Folkes, V. (1984, March).

Consumer reactions to product failure: an attributional approach. Journal of Consumer Research, 10(4), 398-409.

Fornell, C., \&

Wernerfelt, B. (1987, November).

Defensive marketing strategy by customer complaint management: a theoretical analysis. Journal of Marketing Research, 24(3), 337-346.

Fornell, C., \&

Westbrook, R. (1984, July/September).

The vicious circle of consumer complaints, Journal of Marketing, 48(3), 68-78.

Hair, J., Jr.,

Anderson, R.,

Tatham, R., \&

Black, W. (1998).

Multivariate Data Analysis (5th ed.).

Nova Jersey: Prentice Hall.

Hepworth, M. (1997, October).

How to stem revenue loss resulting from customer dissatisfaction. CMA Magazine, 31 .
Hren, G. (1996, March/April).

The sales behind the scowl. Marketing Tools, 4(3), 14-17.

Kinnear, T. C., \&

Taylor, J. R. (1987).

Marketing Research (3th ed.). New York: McGraw-Hill Book Company.

Kotler, P. (1998).

Administração de marketing: análise, planejamento, implementação e controle (5th ed.). São Paulo: Atlas.

Statiscal Package for the Social Sciences (SPSS). (1997).

7.5 for Windows [manual do software]. Chicago, IL: SPSS Inc.

Mittal, V.,

Ross, W. T., \&

Baldasare, P. (1998, January/March).

The asymmetric impact of negative and positive attribute-level performance on overall satisfaction and repurchase intentions. Journal of Marketing, 62(1), 33-47.

Oliver, R. L. (1996).

Satisfaction: a behavioral perspective on the consumer. New York: IrwinMcGraw-Hill.

Richins, M. (1983, January/March).

Negative word-of-mouth by dissatisfied consumers: a pilot study. Journal of Marketing, 47(1), 68-78.

Rossi, C. A. V., \&

Slongo, L. A. (1997).

Pesquisa de satisfação de clientes: o estado-da-arte e proposição de um método brasileiro. Anais do Encontro Nacional dos Programas de PósGraduação em Administração, Rio de Janeiro, RJ, 21. 
Santos, C. P. dos (1996).

A análise do comportamento do consumidor frente às experiências insatisfatórias com eletrodomésticos, na cidade de Santa Maria (RS). Dissertação de Mestrado Porto Alegre: UFRGS/PPGA, 138 p.
Singh, J., \&

Wilkes, R. E. (1996, October/December). When consumers complain: a path analysis of teh key antecedents of consumer complaint response estimates. Journal of the Academy of Marketing Science. 24(4), 350-365.

Wilkie, W. (1994).

Consumer Behavior (3rd ed.). New York: John Wiley \& Sons. 